\title{
DO MANGÁ PARA O DORAMA: A REPRESENTAÇÃO DA IRRITAÇÃO EM NODAME CANTABILE
}

\author{
FROM MANGA TO DORAMA: THE REPRESENTATION OF IRRITATION IN \\ NODAME CANTABILE
}

\author{
DEL MANGÁ PARA EL DORAMA: LA REPRESENTACIÓN DE LA \\ IRRITACIÓN EN NODAME CANTABILE
}

\begin{abstract}
Giovana Santana Carlos Professora do curso de Comunicação Social Jornalismo da Universidade Federal de Viçosa giovanacarlos@ hotmail.com
\end{abstract}

\section{Resumo}

Este trabalho objetiva demonstrar como o dorama (telenovela japonesa), quando uma adaptação de mangá (HQ japonesa), traz consigo características da linguagem dos quadrinhos do Japão, construindo uma estética única, exemplificada aqui pela breve análise comparativa de três cenas de Nodame Cantabile em mangá e em dorama. Entre as características específicas do mangá está o exagero na representação das emoções e sentimentos, resultando em imagens irreais e ao mesmo tempo cômicas. Para demonstrar essa estética e sua presença em diferentes meios, foi escolhida a representação da irritação para comparação em ambas as versões. Serão apresentadas algumas informações acerca da telenovela no Japão, as características dos mangás, assim como os entornos do consumo dessas mídias no Brasil.

Palavras-chave: Dorama. História em quadrinhos. Irritação. Mangá. Telenovela.

\begin{abstract}
The objective of this work is to demonstrate how dorama (Japanese soap opera), when from a manga (Japanese comics) adaptation, brings within characteristics of Japan's comics language, creating a unique aesthetic, exemplified here by the brief comparative analysis of three scenes from Nodame Cantabile in manga and dorama. Among manga's specific characteristics there is the exaggeration in the representation of emotions and feelings, resulting on unreal but at the same time humorist images. To demonstrate this aesthetic and its presence in different media, it was chosen the representation of irritability to compare the versions in each media. It will be shown some information about the Japanese soap opera and manga's characteristics, as well some data about these media consumption in Brazil.
\end{abstract}

Key words: Comics. Dorama. Irritation. Manga. Soap Opera. 


\section{Resumen}

Este trabajo pretende demostrar como el dorama (telenovela japonesa), cuando una adaptación de manga (historieta japonesa) reúne las características de lenguaje de esas historietas, construyendo una estética única, ejemplificada aquí por el breve análisis comparativo de tres escenas de Nodame Cantabile en manga y dorama. Entre las características específicas del manga está la exageración en la representación de las emociones y sentimientos, resultando en imágenes poco realistas y al mismo tiempo cómica. Para demostrar esta estética y su presencia en diferentes medios, elegimos la representación de la irritación para la comparación en ambas versiones. Presentamos informaciones acerca de la telenovela en Japón, las características del manga, así como los entornos del consumo de estos en Brasil.

Palabras clave: Dorama. Historietas. Irritación. Manga. Telenovela.

Esta obra está licenciada sob uma Licença Creative Commons

\section{INTRODUÇÃO}

Há algumas décadas, produtos midiáticos japoneses começaram a entrar timidamente no Ocidente. Atualmente, o Japão fica atrás apenas dos Estados Unidos como exportador desses produtos (GRAVETT, 2006). Se o público brasileiro é acostumado, por exemplo, com o cinema hollywoodiano, hoje também está consumindo quadrinhos (mangás) e desenhos animados (animês) nipônicos. Um produto específico são as telenovelas japonesas, fáceis de serem encontradas na internet. Os doramas são procurados pelos fãs da cultura pop japonesa que já estão acostumados, ou passam a se acostumar, com a estética nova e diferenciada frente ao que estão habituados em termos de audiovisuais, pois são iniciados na representação exagerada das emoções através dos mangás e animês.

Neste trabalho, fazemos uma análise, com o foco específico da representação da irritação, em um título dessas produções japonesas, de forma a demonstrar como um dorama, adaptado de um mangá, é permeado por características dessa mídia impressa. Por isso, trazemos informações sobre a TV e a telenovela na nação oriental, uma vez que não é tão comum seu estudo no Brasil; apresentamos algumas das características dos quadrinhos 
japoneses, enfatizando a representação de emoções; e, por fim, apresentamos Nodame Cantabile para mostrar essa estética específica partindo de uma análise comparativa entre suas versões impressa e televisiva.

\section{DORAMA: A TELENOVELA JAPONESA}

No Japão, a telenovela é chamada de dorama (SATO, 2007), pronúncia japonesa para a palavra drama ${ }^{1}$. Diferentemente do que o brasileiro reconhece como telenovela, essas produções audiovisuais são compostas por episódios semanais, de cerca de 1 hora (40 a 50 minutos sem os intervalos comerciais), totalizando uma média de 10 a 12 capítulos. Algumas apresentam capítulos especiais, geralmente para finalizar a história, com maior duração (por exemplo, duas horas), ou mesmo continuações em temporadas, como os seriados norteamericanos. Os doramas estreiam e duram conforme uma estação do ano, ou seja, os títulos são anunciados para, por exemplo, a estação da primavera (abril a junho) e serão exibidos durante os seus três meses ${ }^{2}$. O horário de transmissão é geralmente à noite, como no Brasil.

Para os brasileiros, tendo em vista as produções ficcionais da televisão nacional as quais estão acostumados, o dorama muito se assemelha às minisséries da Rede Globo, devido aos seus poucos episódios e plots, além de outras características como um cuidado estético mais apurado (mais notável nos primeiros capítulos da telenovela brasileira, como forma de atrair o telespectador). Entretanto, um tipo de telenovela japonesa, conhecida como asadora, é transmitido de segunda a sábado pela manhã (com reprise ao meio dia), por vários meses, resultando em número muito maior de capítulos, com duração diária de 15 a 20 minutos. A NHK é o único canal a transmitir asadora, desde 1961, com a novela Musume to Watashi ${ }^{3}$.

Os primeiros canais de televisão no Japão surgiram em 1953: NHK (Nihon Hoso Kyohai - Japan Broadcasting Corporation), a primeira do país; seguida meses depois pela NTV (Nihon TV), o primeiro canal comercial. No mesmo decênio foram criados os principais canais nipônicos: “TBS (Tokyo Broadcasting System), Asahi Broadcasting Corporation, RKB

\footnotetext{
${ }^{1}$ Além de dorama, também é possível encontrar referências à telenovela japonesa como j-drama, do inglês: japanese drama.

${ }^{2}$ Informações retiradas de http://en.wikipedia.org/wiki/Dorama. Acesso em: 05 fev. 2011.

${ }^{3}$ Informações retiradas http://en.wikipedia.org/wiki/Asadora. Acesso em: 05 fev. 2011.
} 
Mainichi Broadcasting Corporation, Yomiuri Television, Kansai Television, Fuji Television e Mainichi Broadcasting” (NEVES JR., 1998, p.8). Enquanto a NHK é um serviço público, semelhante à britânica BBC, os outros canais são comerciais. Em 1991, havia 103 canais comerciais no país. Conforme Mauro Neves Jr. (idem), a primeira novela da TV japonesa foi Sano no Fue (“A flauta na passagem da montanha"), exibido em 1953, na NHK. A telenovela surgiu no Japão junto com a própria televisão e desde então a preocupação dessas produções é mostrar a cultura e a sociedade japonesa.

De acordo com Neves Jr. (1998), o dorama passou por três períodos de desenvolvimento no Japão: 1953-1964, 1965-1974 e 1975-1988. A primeira década de desenvolvimento (1953-1964) é marcada pela censura do Governo e penetração de audiovisuais norte-americanos até as Olimpíadas de 1964 e começo do crescimento econômico do país. Nessa época, há o surgimento da televisão (tanto o aparelho quanto a transmissão) com diversas restrições como a proibição de exibição de filmes e limitações impostas aos atores de cinema no novo meio pela Japan Motion Picture Association, o que levou à produção de ficção televisionada e importação de audiovisuais, principalmente dos Estados Unidos.

Os doramas dessa década eram caracterizados em grande parte por retratar a vida e os sentimentos da geração dos "jovens homens raivosos" no Japão, isto é, a geração da liberação a qual não havia mais causas para se morrer a favor. Mas, é também, o período de experimentação com doramas New Wave caracterizados pela indiferença à moralidade. Havia também a preferência por doramas ao vivo, isto é, transmitidos em diferentes locações ${ }^{4}$. (NEVES JR., 1998, p.8).

Em 1963, as restrições por parte da associação cinematográfica foram abolidas.

Na segunda década de desenvolvimento (1965-1974), dois gêneros de doramas, que já haviam surgido e existentes até hoje, destacam-se: o centrado em relações familiares/casa

\footnotetext{
${ }^{4}$ No original: "The dramas of this decade were characterized mostly by their portrayal of the feelings and lives of the generation of 'angry young men' in Japan, that is, the generation of the liberation when there were no causes to die for. But, it is also the period of experimentation with New Wave dramas characterized by the indifference to morality. There was also a preference for live dramas, that is, dramas broadcast by relay from different locations" (tradução nossa).
} 
(home dorama) e o histórico (taiga dorama). O home, ou dorama familiar, reflete as mudanças drásticas ocorridas no Japão no pós-guerra, como as alterações na estrutura familiar e a inserção de democracia no país, além de possuir influência de seriados norte-americanos como I Love Lucy e Father Knows Best. Enquanto isso, o taiga traz histórias de detetives (Torimono Cho), viagens aventurosas (Dochu Mono) e femininas.

Nos home doramas é possível perceber as mudanças na estrutura familiar a partir do foco dado aos enredos conforme os anos: a) de 1958 a 1964: retratam grandes famílias, baseadas no sistema patriarcal, e suas relações com a vizinhança; b) de 1964 a 1973: o foco é dado para a mãe como principal membro da família e seu trabalho tanto dentro como fora do lar; c) de 1966 a 1979: a instituição família começa a ser retratada de forma sombria e amarga, num discurso quase que antifamília; d) de 1979 a 1988: abordam perigos e confrontações familiares; e, por fim, e) a partir de 1989 mostram novas estruturas familiares: crianças abandonadas, mães solteiras etc.

Na terceira fase da evolução dos doramas (1975-1988), há uma redução de produções, pois surge a preferência por documentários e novos formatos. Nos anos 1980, se tornam famosos os programas com duplas ou grupos de comediantes (Manzai), principalmente em 1987, ano em que predominam. Algo que repercutirá mais tarde nos doramas, que então centram suas histórias em temas como o bullying, relacionamento amorosos entre professores e alunos, mulheres independentes, mulheres insatisfeitas com o casamento, entre outros não comuns até então.

A partir dos anos 1990, a concorrência entre os canais por programas de notícias e informações levou a era do home dorama à quase um fim e à recriação do gênero. Assim, três novos tipos de doramas começam a aparecer segundo Neves Jr. (1998, p. 14):

o próprio "trendy drama", isto é um dorama não mais concentrado nas relações familiares mas em relações sexuais e de trabalho entre homens e mulheres. Esta forma transferiu o centro de atenção dramática do lar para o local de trabalho. Segundo, o "roller coaster drama", um dorama centrado na busca pelo amor da nova geração de mulheres japonesas trabalhadoras. Finalmente, o "cartoon drama" que tem sua origem em revistas ilustradas, 
de cartuns e de história em quadrinhos do tipo que colocaram o Japão no mais alto rank desse gênero em todo o mundo ${ }^{5}$.

Em 1993, o trendy dá lugar ao new wave dorama, caracterizado pelo texto de roteiristas na faixa dos 30 anos, transmitido em tardes horários noturnos devido à abordagem de assuntos e suspense psicológicos. Nessa mesma época, os home doramas voltam, mas focando nas novas estruturas familiares. Apesar disso, houve uma queda na realização das produções, sendo que os canais Fuji e TBS são hoje os maiores investidores de uma grande quantia de dinheiro e garantem vários horários na grade de programação.

É possível, entretanto, afirmar que há quase que uma especialização entre os canais de TV nacionais em relação aos gêneros dos doramas transmitidos, quando e se o são. Estes canais são NHK, especializada em doramas históricos e séries matinais. NTV, especializada em "trendy dramas" mostrando as novas nuances da sociedade japonesa e doramas jovens, uma mistura de suspense, "ijime" e "cartoon dramas". TBS, a qual ainda explora 'home dramas' e alguns "trendy dramas", Fuji, que quase controla o mercado e é o lar por excelência tanto do 'trendy drama' como dos, especialmente, "roller coster" (na maioria transmitidos às 21:00, especialmente nas segundas-feiras) e new era dramas, e ocasionalmente "cartoon dramas". E finalmente, Asahi, especializada em suspense, séries policiais e "cartoon dramas", (NEVES JR., 1998, p.17)

Como é possível perceber, a maioria dos canais transmite doramas baseados em história em quadrinhos, o que permite supor ser um dos tipos de telenovela mais popular no Japão com grande demanda e quantidade de títulos.

\footnotetext{
${ }^{5}$ No original: “' trendy drama' itself, that is a drama not more concentrated on family relations but on work and sexual relations between men and women. This form transferred the center of dramatic attention from the home to the job-place. Second, the 'roller coaster drama', a drama centered on the search for love of the new generation of Japanese working women. Finally, the 'cartoon drama' which has its origin in cartoon books, comics and illustrated magazines of the kind that have placed Japan in the highest rank of this genre all over the world"'(tradução nossa).

${ }^{6}$ Ijime é a palavra japonesa correspondente à bullying.

${ }^{7}$ No original: "It is possible, however, to affirm that there is almost a specialization among the national TV stations concerning the genres of dramas they tend to broadcast, when and if they do it.These stations are NHK, which specialized in historical dramas and the morning series. NTV, which specialized in 'trendy dramas' showing the new nuances of Japanese society and juvenile dramas, a mixture of suspense, 'ijime' and 'cartoon dramas'. TBS, which still explores 'home dramas' and some 'trendy dramas'. Fuji, which almost controls the market and is the home par excellence of both "trendy dramas," specially 'roller coaster' ones (mostly broadcast at 21:00, especially on Mondays) and new era dramas, and occasionally 'cartoon dramas'. And finally, Asahi, which specialized in both suspense, police series and 'cartoon dramas"' (Tradução nossa).
} 
A seguir será descrito os contextos de consumo e distribuição de telenovelas nipônicas no Brasil.

\section{O DORAMA NO BRASIL}

A principal forma de assistir dorama no país, atualmente, é através da internet, seja online em sites como o youtube ou então via download em sites e blogs especializados no assunto, como o brasileiro Doramas Fans Society (www.doramafanssociety.blogspot.com.br). Esses audiovisuais são adquiridos através de compra do original ou pirata, ou mesmo através de cópia disponível na rede. Um grupo de fãs se organiza e, por conta própria, traduz, edita e disponibiliza na internet para os demais fãs e interessados o audiovisual com as legendas em português, como no exemplo dado acima, ou em outras línguas. Esta prática é chamada de fansubbing, junção das palavras inglesas fan (fã) e subtitle (legenda).

A maioria dos títulos é encontrada com legendas em inglês, assim como as informações sobre as produções. Um exemplo é a DramaWiki (www.wiki.d-addicts.com), wikipédia em inglês na qual é possível encontrar diversas informações sobre os audiovisuais, desde nome dos atores e demais profissionais envolvidos, resumo dos episódios, ibope, curiosidades etc. Não são apenas doramas japoneses, mas também coreanos, chineses e outros orientais, e mesmo filmes. Esse site, principal sobre o assunto, é relacionado ao D-Addicts (www.d-addicts.com), no qual é possível encontrar os episódios para baixá-los. Apesar de ser em inglês, ali são armazenadas legendas em diversas línguas como o português ${ }^{8}$.

Devido ao fenômeno comunicacional da cultura pop japonesa, com o sucesso dos animês (desenhos animados) seguidos pelos mangás, a partir dos anos 1990 e início deste século, surgiu uma forte demanda por produtos japoneses. A indústria de entretenimento do Japão é bastante integrada, por isso é comum a mesma história, com alterações, sair dos quadrinhos para a TV (séries, especiais, desenhos animados, telenovelas), para o cinema, vídeo games etc. Devido a essa característica transmidiática, ou seja, o que Henry Jenkins (2008) denomina como a circulação de um conteúdo pertencente a um mesmo universo em várias e diferentes mídias, surgiu a tendência de o público ocidental, aqui em específico o

\footnotetext{
${ }^{8}$ Em abril de 2012 havia 40 títulos com legendas em português disponíveis para baixar no site (http://www.daddicts.com/forum/subtitles.php\#Portuguese).
} 
brasileiro, buscar inicialmente as adaptações dos mangás já conhecidos em doramas, e viceversa.

No Brasil, não há por enquanto iniciativas por parte de empresas de licenciar doramas em DVD, muito menos de canais de TV aberta transmiti-los, com as poucas exceções que logo serão dadas. Por isso, hoje a única forma de assistir tais produções é através da importação do DVD, da internet (download ou online) ou empréstimo em locadoras especializadas (encontráveis em cidades com predominante comunidade japonesa, como em São Paulo, no bairro da Liberdade).

Apesar desse cenário, a televisão brasileira já transmitiu nacionalmente uma asadora e um dorama: a primeira foi Oshin e, anos mais tarde, Haru e Natsu, as cartas que não chegaram.

Exibido em mais de 40 países, Oshin foi a telenovela japonesa mais vista no Japão, com 62,9 pontos percentuais de audiência (SATO, 2007). O enredo é sobre uma garota, que dá nome à asadora e significa perseverança, que passa por diversas adversidades e sofrimentos durante sua vida ${ }^{9}$. A história retrata um Japão e, principalmente, a mulher japonesa, desde antes da $2^{\text {a }}$ Guerra Mundial até os anos 1980. Exibida entre abril de 1983 a março de 1984, teve 300 capítulos de 15 minutos cada. Também possui adaptações para o cinema, em animê e mangá. Conforme Cristiane A. Sato (2007, p. 325),

no Brasil Oshin foi a principal causa da venda de aparelhos de videocassete domésticos betamax. Em 1984, quando nem os videocassetes VHS ainda eram populares, as empresas Sony e Sanyo fabricaram no país os beta para atender a comunidade nipo-brasileira, pois as locadoras especializadas que tinham cópias de Oshin trabalhavam apenas com este sistema, então o mais usado no Japão. Tamanha foi a popularidade da novela na colônia japonesa, que alguns anos depois Oshin chegou a ser exibida em TV aberta no Brasil, com som original e sem legendas, como atração do programa "Imagens do Japão".

\footnotetext{
${ }^{9}$ A história começa com Oshin idosa contando sua vida e de sua família ao neto. Aos 8 anos a menina é tirada de casa para trabalhar como empregada doméstica, em um regime quase de escravidão. Ela foge e passa a viver nas ruas. Já adulta se casa e abre comércio com o marido, mas logo perdem tudo, o que os obriga a ir morar com os pais do marido. Lá, Oshin é discriminada e tratada como empregada. Depois de vários outros sofrimentos, como aborto, perda de um filho na $2^{\mathrm{a}}$ guerra, e suicídio do marido, ela consegue se superar e torna-se empresária rica de uma rede de supermercados.
} 
Como é possível perceber, essa produção concentrou-se basicamente na comunidade de japoneses e descendentes do país ${ }^{10}$, ficando restrita aos que detinham o conhecimento da língua japonesa.

Em 2008, foi comemorado no Brasil o centenário de imigração japonesa, e como parte do festejo, o canal Band exibiu o dorama: Haru e Natsu, as cartas que não chegaram. Três anos antes, o audiovisual havia sido exibido no Japão como comemoração dos 80 anos da primeira transmissão da NHK para o Brasil (na TV paga). Através de oito episódios é contada a história de duas irmãs, cujos nomes são Primavera (Haru) e Verão (Natsu), separadas ainda crianças quando a família imigra para o Brasil. São retratas suas vidas durante a infância até a velhice, cada uma em um país com sua luta pela sobrevivência ${ }^{11}$. Muitas cenas da família trabalhando nas plantações de cafés e outras foram gravadas em Campinas/SP. Devido à temática, o dorama é bilíngue (japonês e português). A exibição no Brasil ocorreu de 25 de fevereiro a 7 de março, às 22 horas $^{12}$. Neste caso, o dorama pôde ser visto por todo e qualquer público brasileiro interessado, pois junto às falas em japonês havia legendas em português.

Os dois exemplos aqui apresentados foram os únicos encontrados que foram transmitidos na TV brasileira, em rede nacional. É bastante possível que outras produções tenham sido exibidas em canais regionais, onde a comunidade nipo-brasileira é concentrada. É válido lembrar que, desde a década de 1960, já eram exibidos no Brasil live actions japoneses, conhecidos como tokusatsu, como Kamen Rider, Jaspion, Changeman e outros, porém estes se tratam de seriados, com muito mais episódios e temporadas do que os doramas, com um público-alvo e temáticas diferenciados, uma vez que essas produções destinam-se para um público infanto-juvenil (o que, é claro, não impede muitos adultos de assistirem e comporem um público significativo) e concentram-se em aventuras fantasiosas como salvar o planeta.

\footnotetext{
${ }^{10}$ O Brasil é o país no mundo com a maior comunidade de japoneses e descendentes fora do Japão, somando 1 milhão e meio de pessoas, sendo que $70 \%$ concentra-se em São Paulo. (Dados do livro Cultura pop Japonesa da editora JBC)

${ }^{11} \mathrm{O}$ enredo gira em torno da família Takakura, que vem ao Brasil em busca de sustento, para depois voltar ao Japão. Mas, Natsu é impedida de viajar devido a uma doença (tracoma ocular). Assim, as irmãs prometem escrever cartas, que acabam não chegando à destinatária. Como aconteceu com boa parte dos japoneses, a família não consegue retornar à pátria. Após 70 anos, Haru volta ao Japão, junto com o neto que pretende morar lá, para procurar a irmã, que pensava ter sido esquecida.

${ }^{12}$ As informações foram retiradas de: www.overmundo.com.br/overblog/haru-e-natsu-as-cartas-que-nao-foramentregues, www.band.com.br/fiquedeolho/conteudo.asp?ID=66206\&CNL=18

www.pt.wikipedia.org/wiki/Haru_e_Natsu_-_As_cartas_que_não_chegaram. Acessos em: 7 dez. 2009.
} 


\section{O EXAGERO NA REPRESENTAÇÃO DE EMOÇÕES NO MANGÁ}

Quando abordadas as características da linguagem dos mangás nos concentramos, sobretudo, na representação dos sentimentos, a qual geralmente é exacerbada, extravasada de maneira irreal, ou pelo menos, quase irreal. Esta e outras características já se tornam marca comum ao redor do mundo, tanto que estão surgindo em vários países mangás de diversas nacionalidades com o rótulo "estilo mangá" ". Alguns exemplos dessa característica de extravasamento de sentimentos são: tombos, quando o personagem fica abismado com alguma coisa ele cai; agressões, como socos, tapas, batidas e chutes, os quais enfatizam arrombos de emoções, nervosismos, irritações; choros, as lágrimas em excesso podem ser tanto para algo triste quanto feliz, ao lembrar de alguma história infeliz ou ao receber uma notícia ótima.

Para quem não é acostumado com os quadrinhos japoneses, ou cartoon doramas, estes exemplos podem não mostrar nada de muito diferente do que um brasileiro já possa ter visto nas telenovelas nacionais, por exemplo. Entretanto, a diferença está no momento em que estes extravasamentos acontecem, pois se tratam de um recurso estético escolhido para ser utilizado: no caso do uso de choro para alguns momentos, por exemplo, esse choro pontua de forma enfática o que acontece, não se trata do personagem estar chorando de fato. É como quando um personagem de desenho fica tonto, após ter batido a cabeça, e aparecem pássaros voando ao redor de sua cabeça: as aves não estão realmente ali, elas apenas aparecem para representar a tontura. Assim como o público ocidental já tem consolidado este tipo de representação, o dos passarinhos, o público japonês tem seus próprios códigos de representar o mundo de maneira única, muitas delas consagradas por suas histórias em quadrinhos.

Os exageros na representação, principalmente, de sentimentos e emoções nos mangás, resultando em "deformações" de rostos e irrealidade de movimentações dos personagens são chamados por Amaro Braga Jr. (2005, p. 90) de "metalinguagem de tendência cômica". Os principais exemplos são

\footnotetext{
${ }^{13}$ No Brasil, o caso mais notório é o lançamento, em 2008, da "Turma da Mônica Jovem", em que os personagens de Mauricio de Sousa, são reapresentados como adolescentes. Em toda edição é estampada na capa uma espécie de selo dizendo "em estilo mangá".
} 
as caretas presentes em todos os tipos de histórias, por mais séria que seja; As gotas de lágrima, e de secreção nasal, ampliadas, muitas vezes maiores que os rostos dos personagens; Os socos, pontapés e cascudos físicos, assim como as quedas "de-pernas-para-o-alto" e as miniaturas de personagens [...] Estas metalinguagens são utilizadas na tentativa de enfatizar os diálogos, e que normalmente são ações que visam simplesmente uma representação simbólica das expressões e dos diálogos textuais.

Outras características dos mangás é a de que a narrativa é mais visual em comparação com os quadrinhos ocidentais, pois o narrador é pouco utilizado e os diálogos acontecem de forma direta, dando fluidez e ritmo suave às obras (NAGADO, 2007). Isto se deve em parte à utilização da linguagem cinematográfica, dando destaque para olhares, ações e gestos dos personagens. Outros recursos utilizados, conforme Patrícia Borges são (2009, p. 33):

as linhas de movimento, a disposição mais solta dos textos, a diagramação livre, a ampla variedade de cores e estilos tipográficos, os enquadramentos, além de diversos fatores relacionados às personagens. No que se refere ao seu design, eles possuem traços simplificados, geralmente são altos e magros, seus cabelos são coloridos e os olhos enormes e expressivos. Em relação às suas características individuais, todas e quaisquer personagens, assim como os heróis e heroínas possuem características humanas: são pessoas comuns que nascem, crescem, envelhecem, enfrentam problemas no dia-a-dia etc".

Esclarecida essas questões, em seguida será apresentado e analisado o cartoon dorama Nodame Catabile, em relação à presença de características da linguagem das histórias em quadrinhos japonesas.

\section{O DORAMA NODAME CANTABILE E AS CARACTERÍSTICAS DOS MANGÁS}

Nodame Cantabile conta a história de Noda Megumi, apelidada de Nodame, e Shinichi Chiaki, estudantes de Música da Universidade Momogaoka, no Japão. Inicialmente, ambos estudam piano, porém Chiaki deseja ser maestro, mas um trauma causado por um acidente de avião o impede de seguir seu sonho, pois maestros precisam viajar pelo mundo.

Enquanto Nodame é desleixada e "aérea", Chiaki é organizado e perfeccionista, seja para a música ou para a vida. Assim, como opostos, os dois se encontram e vão se ajudando, mesmo sem perceberem, a tornar seus sonhos em realidade, ao mesmo tempo em que vão 
amadurecendo: ela em busca de ser uma pianista, ele, um maestro. Ambos enfrentam concorrentes, professores, concursos e até mesmo adversários no amor (Nodame desde o início se apaixona pelo rapaz, o qual a ignora até boa parte da trama).

Entre os personagens coadjuvantes, se destacam: Okuyama Masumi, percursionista, inicialmente rivaliza com Nodame por Chiaki; Miki Kyora, violinista, amigo do casal; e o professor maestro Franz Strezemann (Milch Holstein), o qual sempre dá conselhos, sobre música e amor, para os protagonistas.
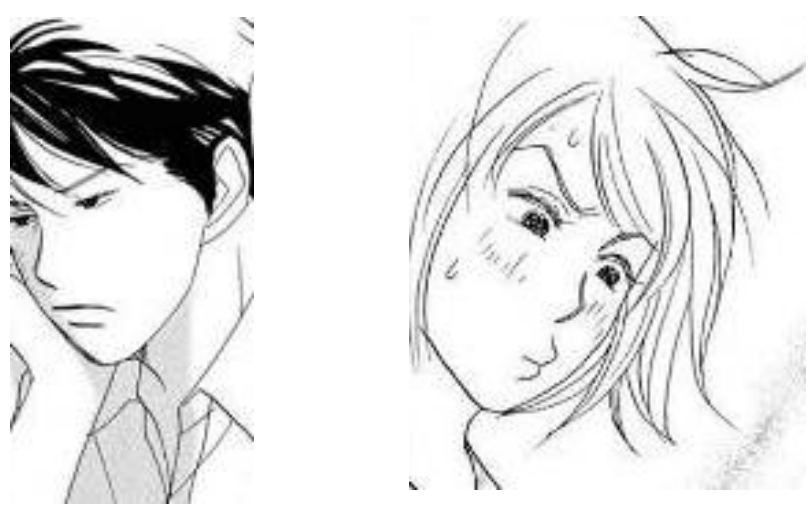

Figura 1 e 2 - Os protagonistas Shinichi Chiaki e Noda Megume.

(Fonte: http://www.fanservice.com.br/site/projetos.php?id=4 - 2010.)
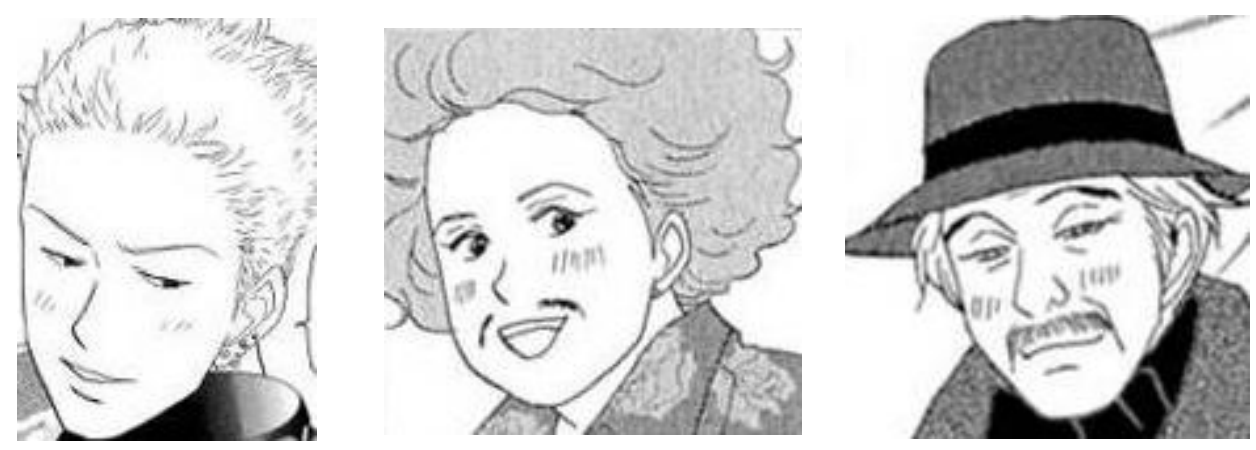

Figura 3, 4 e 5 - Os coadjuvantes Miki Kyora, Okuyama Masumi e Franz

Strezemann. (Fonte: http://www.fanservice.com.br/site/projetos.php?id=4 - 2010.)

A história original foi criada por Tomoko Ninomiya inicialmente em mangá, entre julho de 2001 e outubro de 2009, em um total de 23 volumes. Além do dorama, também foi 
produzido um animê, dividido em três temporadas: a primeira com 23 episódios, de cerca de 25 minutos cada, exibidos em 2007; e a segunda, com 11 episódios, transmitidos em 2008; e a última, também com 11 episódios, exibidos em 2010.

O dorama foi ao ar pela TV Fuji, nas segundas-feiras, às 21 horas, de outubro a dezembro de 2006, num total de 11 episódios. Além de contar com dois especiais, de cerca de 2 horas cada, exibidos em janeiro de 2008; e dois longa-metragens, intitulado Nodame Cantabile: Final Movement, o primeiro estreou nos cinemas japoneses em dezembro de 2009 e o segundo em abril de 2010. Tanto os especiais quanto os filmes são continuações do dorama, portanto o segundo filme é a última produção, já que chega ao final do enredo.

Algumas especificidades é a de que, como se passa em uma universidade de Música, os episódios são repletos de cenas de orquestras, assim como cenas dos personagens tocando seus instrumentos específicos (piano, tímpano, violino, oboé, violoncelo). Assim, o tom sóbrio de uma orquestra ao se apresentar pode parecer, inicialmente, contrastante com as cenas que remetem às características da linguagem dos mangás, as quais são extremamente caricatas e cômicas.

Mas, antes de iniciar a análise, algumas considerações são importantes para a compreensão das escolhas deste trabalho. Primeiramente, a decisão de se debruçar sobre um cartoon dorama é em parte por acreditar que o público ocidental, aqui especificamente o brasileiro, começou a procurar doramas principalmente para ir atrás da versão da história que já havia lido em mangá ou assistido em animê. Assim, ao conhecer esses audiovisuais baseados em quadrinhos passou também a buscar pelos mais variados temas, não mais somente as adaptações. Em segundo lugar, a escolha do cartoon dorama Nodame Cantabile para análise se deve ao fato de, dentro do repertório da autora, ser um audiovisual bastante marcado pela sua origem nos quadrinhos, trazendo para a encenação, com pessoas reais, expressões corporais (gestos, posturas) característicos da linguagem do mangá, marcada pelo exagero e iconicidade na representação de sentimentos. Nem todos os audiovisuais com base em mangás trazem fortemente essa herança do material impresso, porém julgou-se que o título escolhido, mais do que trazê-la, chega por vezes a criar essa especificidade em momentos em que não há equivalência nos quadrinhos. 


\section{A ANÁLISE COMPARATIVA DE NODAME CANTABILE ${ }^{14}$}

Para evidenciar a utilização da linguagem dos mangás, em específico, a característica do exagero na representação de um sentimento/emoção, nos concentramos em três cenas tiradas do primeiro episódio de Nodame, cujas correspondentes aparecem no primeiro e segundo volume do mangá (nos capítulos 1, 3 e 10, respectivamente). São cenas curtas, nas quais é representada a irritação de dois personagens através de agressões. Desde já é preciso esclarecer que as cenas podem parecer violentas para quem as vê isoladamente, mas são extremamente ficcionais, e constituem alguns dos momentos mais cômicos do episódio.

Explicados os pontos anteriores, é importante destacar que a própria caracterização dos personagens já mostra algo de caricato no dorama, principalmente os personagens secundários. Os cabelos de Masumi, Miki e Strezemann dão a impressão de terem saído de alguma obra ficcional, ainda mais se somando suas roupas. Todavia, mais do que isso, são seus gestos faciais e corporais em conjunto com certas ações que os remetem diretamente ao mangá. As caretas de Masumi quando o assunto é seu objeto de desejo, o Chiaki, são sempre fortes, com olhos apertados e beicinhos. Outro caso é o do professor alemão Strezemann, que na condição de estrangeiro, acaba sendo mais exagerado em suas posturas, visão dos japoneses em relação aos ocidentais.
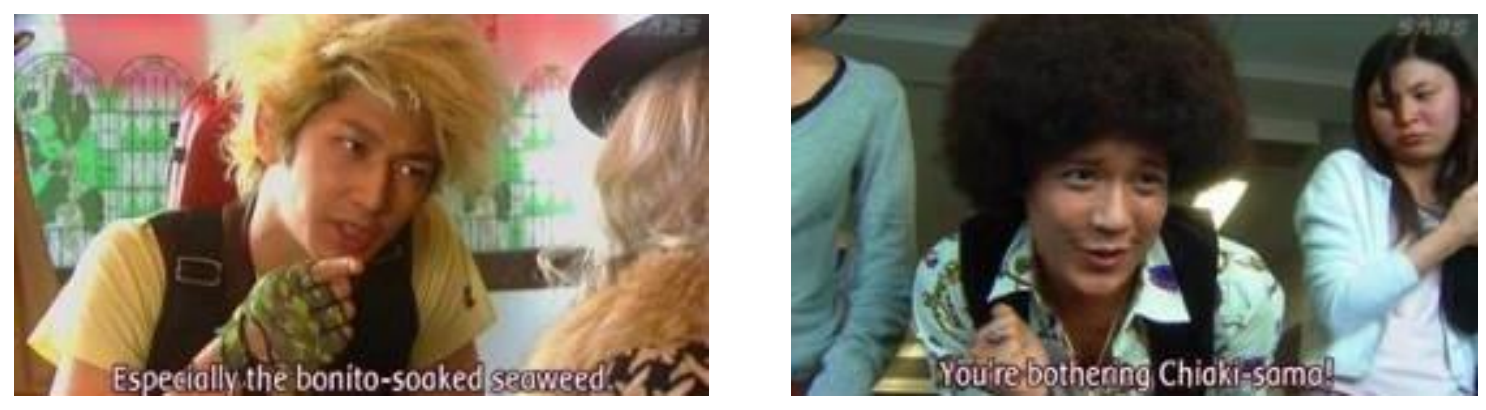

Figura 6 e 7 - Miki Kyora e Okuyama Masumi.

(Fonte: http://www.sars-fansubs.com/downloads/ - 2010.)

\footnotetext{
${ }^{14}$ Todas as imagens aqui utilizadas foram coletadas a partir da internet, com traduções feitas por fãs. O dorama (traduzido para o inglês) foi retirado do site www.sars-fansubs.com e o mangá (traduzido para o português) do http://fanservice.wordpress.com/.
}

ANIMUS R. Interamericana de Comunicação Midiática, http://www.ufsm.br/revistas E-ISSN 2175-4977, v. 11, n. 21, Jan-Jun(2012) 


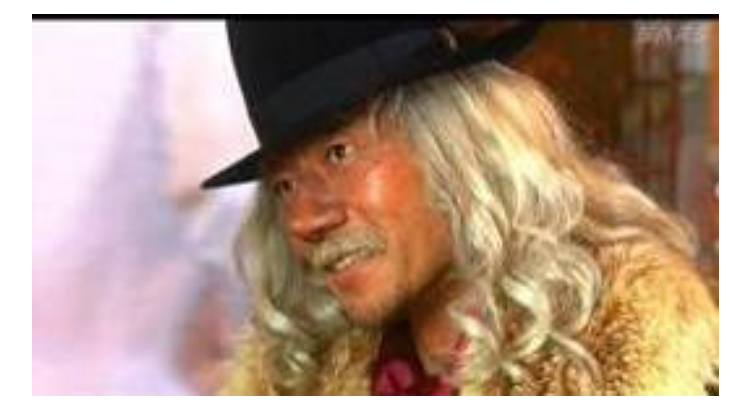

Figura 8 - Franz Strezemann. (Fonte: http://www.sars-fansubs.com/downloads/ - 2010.)

Além disso, certas cenas enfatizam a ficcionalidade da obra como a de Nodame correndo de forma desajeitada pelos corredores ou pulando como criança, ou a de Chiaki tremendo exageradamente ao lembrar de seu acidente de avião. Mas, apesar desses vários exemplos, as três cenas a seguir dão conta de exemplificar melhor o que este trabalho propõe:

CENA 1 (6'08', - 6'36')

Quando Chiaki está tocando piano, o professor chega por trás e com um enorme leque bate na cabeça do rapaz gritando-lhe: "o que você está fazendo?”. Ao realizar este ato - em slow motion -, o professor pula em sua direção e, ao ser agredido, a cabeça de Chiaki vira-se, sua boca se abre e expele várias gotículas de baba, sendo derrubado ao chão junto com suas partituras.

Esta cena pode surpreender, pois o professor Eto chega de forma despercebida e a ação tomada por ele parece extremamente violenta. Entretanto, o que acontece é que há um exagero das emoções, e reações, para a situação que poderia ser encenada sem o professor bater com o leque no aluno, uma vez que mostra Eto discutindo com Chiaki para que este tenha uma postura mais séria em relação à música. Assim, ao invés de simplesmente o professor chegar e falar o que deseja, há a representação no mundo concreto através de gestos e caretas, de algo que poderia ficar simplesmente no mundo simbólico, ou seja, nas palavras e na interiorização dos sentimentos. O que o professor tem a dizer a Chiaki o agride e o "derruba", com ou sem o leque. 

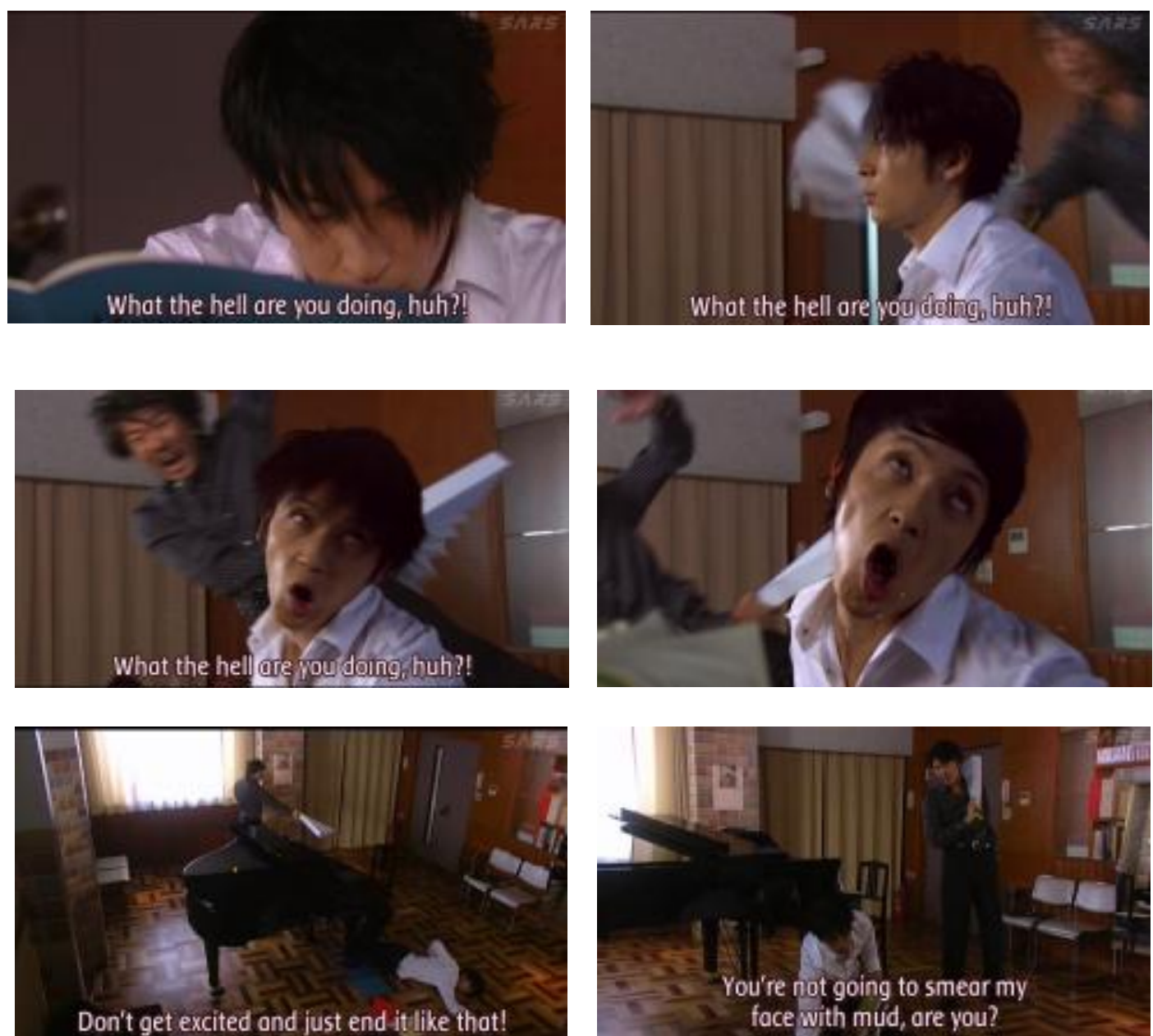

Figura 9 - sequência da Cena 1 em que o professor Eto bate em Chiaki.

(Fonte: http://www.sars-fansubs.com/downloads/ - 2010.) 


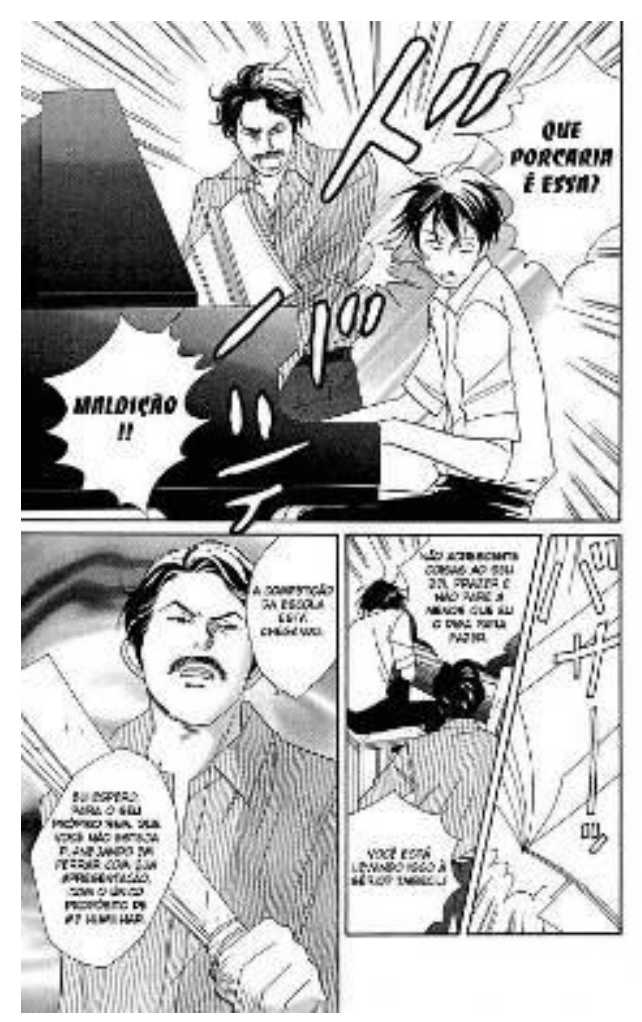

Figura 10 - Cena 1 correspondente no mangá.

(Fonte: http://www.fanservice.com.br/site/projetos.php?id=4 - 2010.)

CENA 2 (22'04' - 22'45')

Nodame e Chiaki estão em aula e o professor pede para que os dois toquem juntos uma peça de Mozart. Logo no início, Chiaki se aborrece com Nodame, pois a garota não está seguindo a partitura. Então, ele pega a própria partitura e joga em sua direção, gritando para ela parar de errar. A força com que ele joga os papéis parece enorme e, quando o material atinge a garota, ela cai do banco de maneira abrupta. A princípio, parece que irá colidir com a câmera, embora não aconteça, e antes de cair ainda vemos a sua perna no alto, enfatizando o tombo. Novamente aqui é utilizado o slow motion para o ato de agressão e, enquanto está caindo, vemos os olhos de Nodame lacrimejar enormemente.

Em nova tentativa, os dois começam a tocar. Chiaki continua irritado com a maneira desajeitada de Nodame. Então, pega sua partitura, levanta-se, vai até atrás dela e bate em sua cabeça com o calhamaço de papel, fazendo-a bater com a cabeça no piano. Por um breve momento aparecem desenhadas sobre Nodame algumas estrelas, sugerindo tontura. A 
sensação é a de que sua cabeça é esmagada no instrumento, pois suas mãos aparecem espalmadas contra o piano.

Como na cena anterior, esses atos exagerados não seriam necessários, uma vez que o rapaz poderia simplesmente chamar a atenção da garota para seus erros sem grandes conflitos. Mas, para dar ênfase ao incômodo de Chiaki, o qual é extremamente perfeccionista, há esse extravasamento de irritação com a colega.
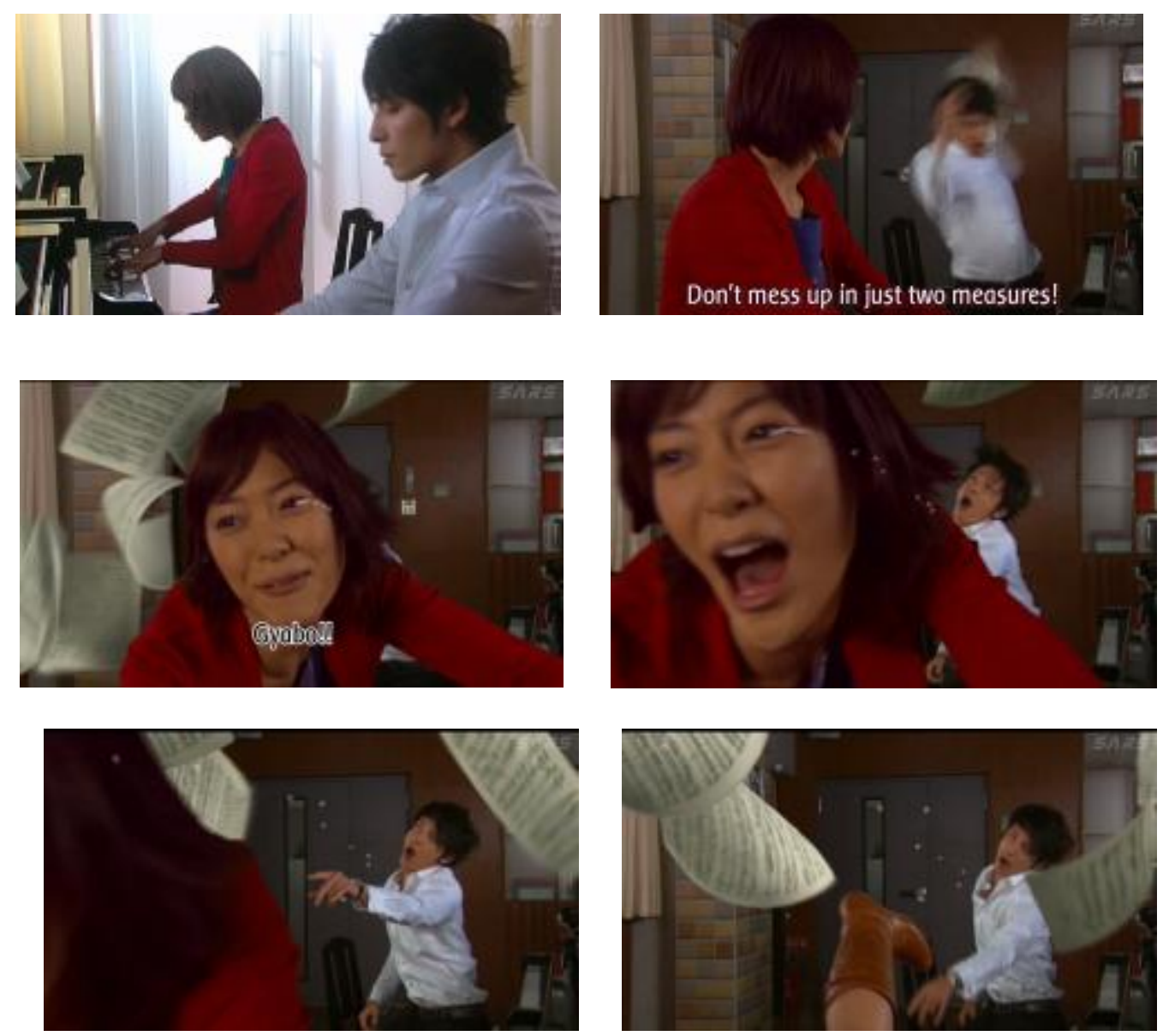

Figura 11 - Cena 2 na qual Chiaki joga as partituras em Nodame por causa do seu erro.

(Fonte: http://www.sars-fansubs.com/downloads/ - 2010.)
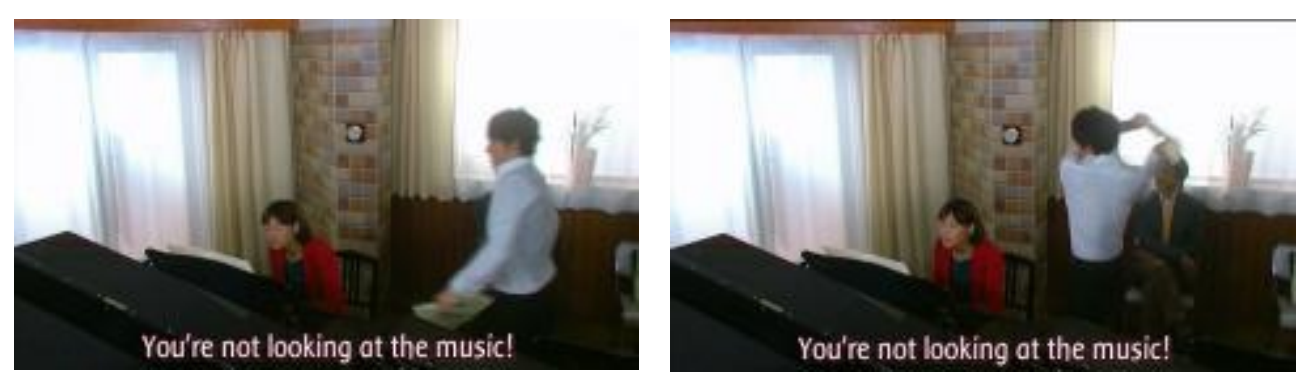

ANIMUS R. Interamericana de Comunicação Midiática, http://www.ufsm.br/revistas E-ISSN 2175-4977, v. 11, n. 21, Jan-Jun(2012) 

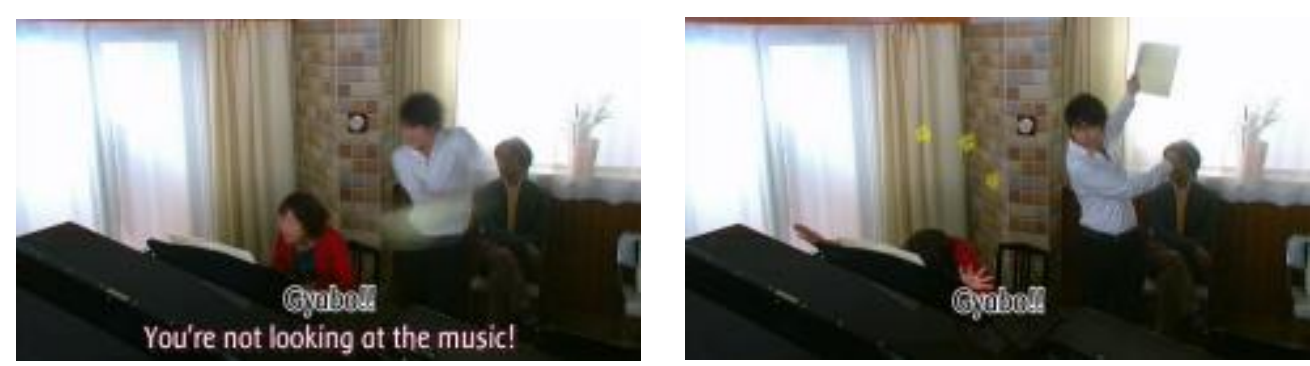

Figura 12 - outra sequência da Cena 2 na qual Nodame erra novamente e Chiaki bate em sua cabeça com as partituras. (Fonte: http://www.sars-fansubs.com/downloads/ - 2010.)
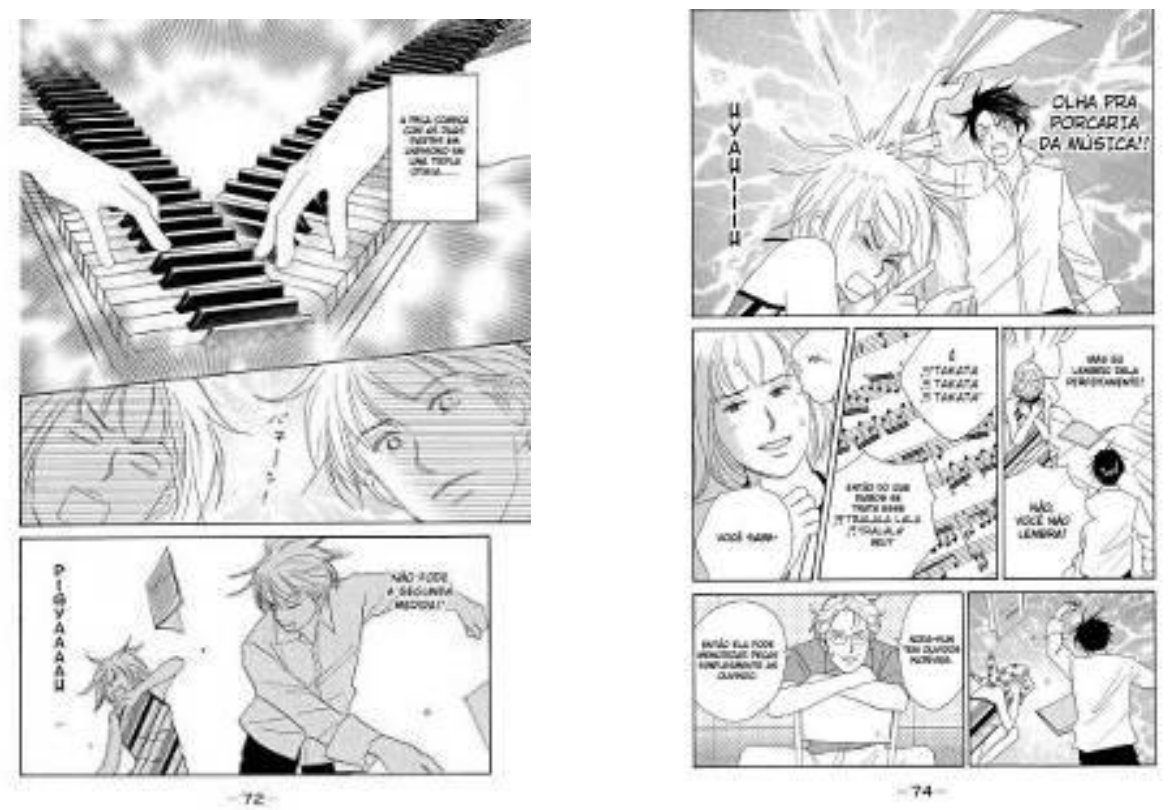

Figura 13 e 14 - Sequências da Cena 2 correspondentes no mangá. (Fonte: http://www.fanservice.com.br/site/projetos.php?id=4 - 2010.)

CENA 3 (38'51', - 39'15')

Chiaki entra em seu quarto e Nodame está em sua cama, convidando-o a juntar-se a ela. Ele fica bravo, vai em sua direção, dá-lhe um chute, puxa-a para fora da cama e a arrasta até a sala. A garota consegue se soltar e promete estudar com ele, o que era o combinado para ela estar ali.

Desta vez não é utilizado o recurso de slow motion, mas a mesma sensação de que Nodame vai se bater na câmera acontece, assim como ela manter a perna levantada, característica comum nos mangás. Aqui isso fica muito visível porque Nodame fica vários segundos parada na mesma posição, como se fosse mesmo um desenho. 

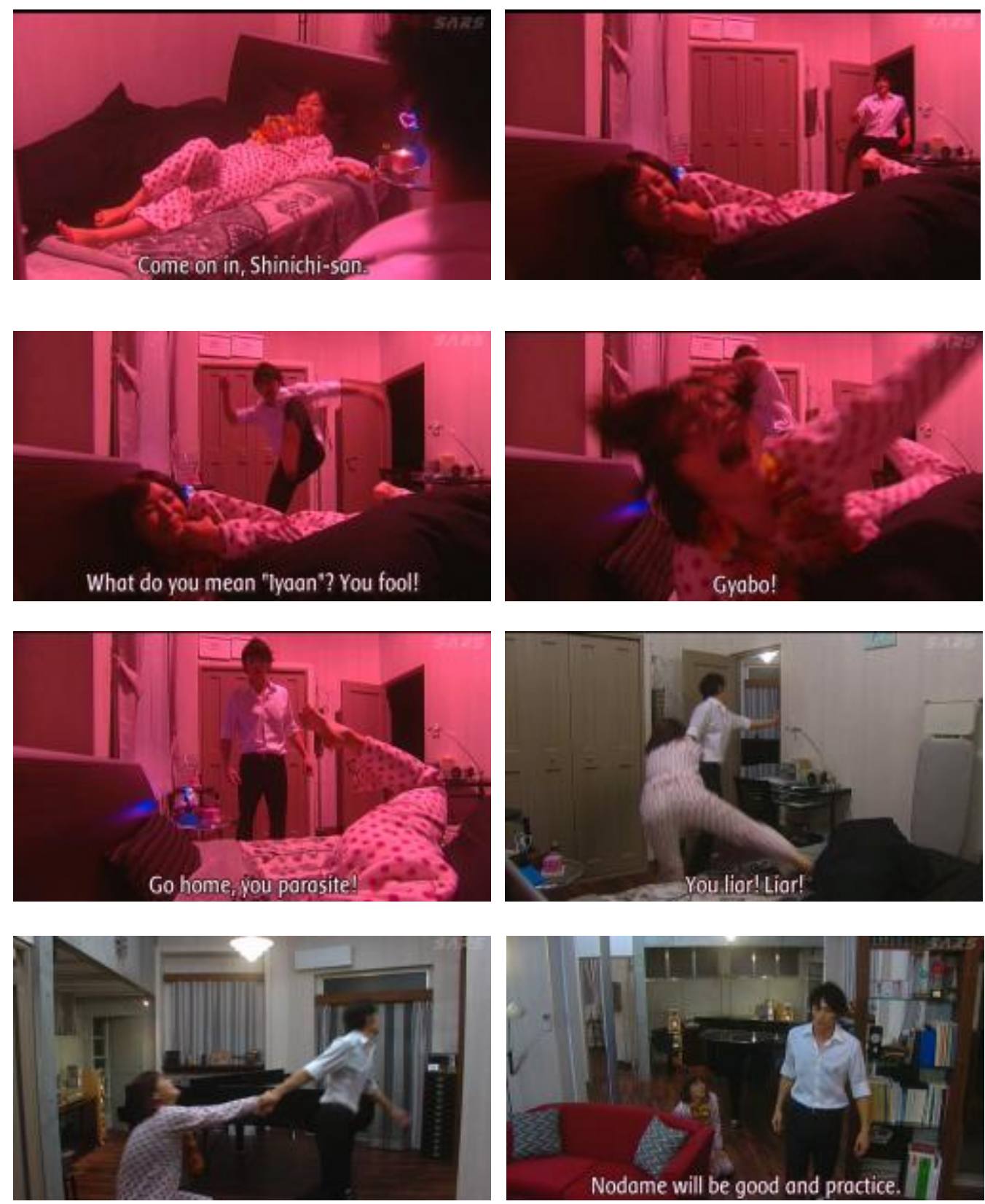

Figura 15 - Cena 3 na qual Chiaki encontra Nodame em seu quarto.

(Fonte: http://www.sars-fansubs.com/downloads/ - 2010.) 

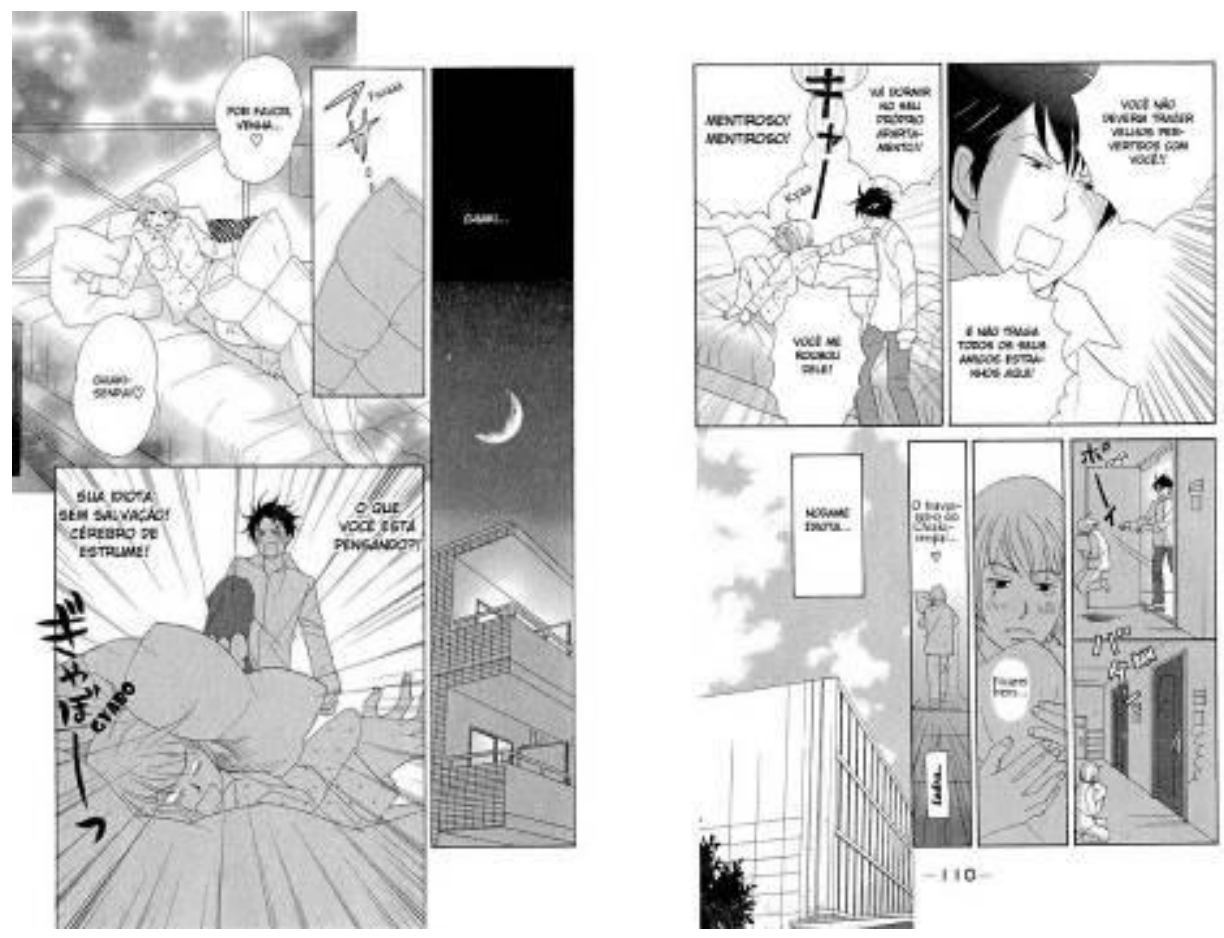

Figura 16 - Cena 3 correspondente no mangá.

Fonte: http://www.fanservice.com.br/site/projetos.php?id=4 - 2010.)

A representação da irritação dos personagens através de agressões nestas três cenas trazem consigo uma herança da linguagem das histórias em quadrinhos japonesas. Primeiro, pela própria forma exagerada de representar este sentimento, em segundo pela forma que os personagens caídos, depois da agressão, se mantêm por alguns segundo imóveis (o corpo estatelado, as mãos espalmadas e as pernas levantadas), e em terceiro pelo recurso de slow motion utilizado. Sobre este último ponto, Lan Xuan Le (2009, p. 85) comenta como o recurso é utilizado pelos quadrinhos japoneses:

o mangá frequentemente foca e alarga um único momento, estudando-o com um interesse de um poeta ou cientista. Esta técnica de cinema do 'slow motion' literalmente fragmenta e acumula o fluxo do tempo para examinar seus componentes como uma obra de arte moderna ${ }^{15}$.

\footnotetext{
${ }^{15}$ No original: "manga often zooms into and stretches out a single moment, studying it with the interest of a poet or scientist. This 'slow motion' cinematic technique literally fragments and accumulates the flow of time to examine its components like a piece of modernist art" (Tradução nossa).
} 
Entretanto, estas são apenas algumas cenas do mangá adaptadas no dorama demarcado como cartoon dorama. Muitas outras, até mesmo diferenciadas poderiam ser levantadas. $\mathrm{O}$ importante é observar que mais do que levar uma história para um suporte diferenciado, do impresso para o audiovisual, temos aqui um caso em que características estéticas do meio original são levadas e trabalhadas para um outro meio. Ao mesmo tempo em que estas características se mantêm, elas sofrem algumas alterações, embora mantendo a sua essência.

No Ocidente, semelhante seriam as adaptações cinematográficas de quadrinhos, como 300, de Frank Miller, e The Spirit, de Will Eisner. Entretanto, a comparação geralmente se mantém para as cenas de ação cuja tentativa de remeter ao quadro da HQ acaba por levar ao uso do slow motion. E mesmo que haja socos e ponta-pés, como os mostrados anteriormente, geralmente não são tantos e tão caricatos como nas produções japonesas e em situações cotidianas, como no dorama aqui apresentado cujo enredo se passa em ambiente universitário e focado na música, sem nenhum momento permitir a classificação de "ação", num sentido de luta. É claro que com a assimilação do Ocidente pelos produtos midiáticos japoneses, a estética aqui comentada tem se disseminado em produções ocidentais, como em Matrix (1999), dos irmãos Wachowski, os quais afirmaram se basear no animê "O Fantasma do Futuro" (Ghost in the Shell -1995) para a realização de sua película, além de filmarem a versão hollywoodiana de Speed Racer (2008), também oriundo dos mangás, mais conhecido no Ocidente pelo animê. Mas ainda assim é possível verificar a diferença entre as produções ocidentais que se utilizam dessa estética, tornando produções japonesas como os doramas únicas.

\section{CONSIDERAÇÕES}

O trabalho aqui apresentado buscou apresentar a estética marcante da representação exagerada das emoções, em específico a da irritação, característica nas histórias em quadrinhos japonesas presentes em outras mídias, como na telenovela japonesa. Assim, foram resgatadas algumas informações sobre as telenovelas japonesas, conhecidas como doramas. Após uma breve retrospectiva histórica, concentramo-nos no cartoon dorama, ou seja, a telenovela japonesa baseada em mangá, os quadrinhos japoneses. Esta decisão foi tomada devido ao fato de os mangás fazerem sucesso no Brasil, assim como boa parte do Ocidente, e levarem seus fãs a buscarem as versões televisivas dessas obras. Explicado rapidamente todo 
este panorama de consumo do dorama, partimos para uma análise de Nodame Cantabile de forma a evidenciar como características dos mangás são levadas até a televisão japonesa nessas produções ficcionais.

As constatações aqui feitas levam a diversas indagações a cerca da realização de audiovisuais e consumo. Entre elas, a estética do mangá, assim como sua forma de representar certas situações, como fonte inspiradora para a criação de produções fora do Japão e, principalmente, a experiência estética a que este público brasileiro, e ocidental, expõe-se, uma vez que tais composições de imagens e cenas são incomuns no mundo ocidental, principalmente, brasileiro.

\section{REFERÊNCIAS}

BRAGA JR., Amaro. Desvendando o mangá nacional: reprodução ou hibridização? Uma abordagem sociológica sobre o fenômeno das histórias em quadrinhos japonesas no Brasil. 2005. Dissertação (Mestrado em Sociologia) - Universidade Federal de Pernambuco, Recife, 2005.

BORGES, Patrícia. Traços ideogramáticos na linguagem dos animês. São Paulo: Via Lettera, 2008.

JENKINS, Henry. Cultura da convergência. São Paulo: Aleph, 2008.

LE, Lan Xuan. Imaginaries of the Asian Modern: Text \& Context at the Juncture of Nation and Region. Disponível em: 〈http://cms.mit.edu/research/theses/LanLe2009.pdf>. Acesso em: 10 nov. 2009.

NAGADO, Alexandre. Almanaque da cultura pop japonesa. São Paulo: Via Lettera, 2007.

NEVES JR., M. Reflecting society: TV dramas in Brazil and Japan. Disponível em: <http://orpheus.ucsd.edu/las/studies/pdfs/neves.pdf>. Acesso: 5 dez. 2009.

SATO, Cristiane A. Japop: o poder da cultura pop japonesa. São Paulo: NSP-Hakkosha, 2007.

Original recebido em: 03-02-2011

Aceito para publicação em: 10-07-2012 
Giovana Santana Carlos é formada em Jornalismo pela Universidade de Passo Fundo, Mestre em Comunicação e Linguagens pela Universidade Tuiuti do Paraná (UTP) e professora do curso de Comunicação Social - Jornalismo da Universidade Federal de Viçosa (UFV). 